\title{
Six 1 is indispensable for production of functional progenitor cells during olfactory epithelial development
}

\author{
KEIKO IKEDA ${ }^{1}$, RYOICHIRO KAGEYAMA ${ }^{2}$, YUKO SUZUKI ${ }^{3}$ and KIYOSHI KAWAKAMI*,1 \\ ${ }^{1}$ Division of Biology, Center for Molecular Medicine, Jichi Medical University, Shimotsuke, Tochigi, Japan \\ ${ }^{2}$ Institute for Virus Research, Kyoto University, Sakyo-ku, Kyoto and ${ }^{3}$ Division of Histology, Department of Oral Growth \\ and Development, School of Dentistry, Health Sciences University of Hokkaido, Ishikari-gun, Hokkaido, Japan
}

\begin{abstract}
The rodent olfactory epithelium (OE) is a good model system for studying the principles of stem and progenitor cell biology, because of its capacity for continuous neurogenesis throughout life and relatively well-characterized neuronal lineage. The development of mouse $\mathrm{OE}$ is divided into two stages, early and established neurogenesis. In established neurogenesis, which starts at embryonic day (E) 12.5, sustentacular cells and olfactory receptor neurons (ORNs) are produced

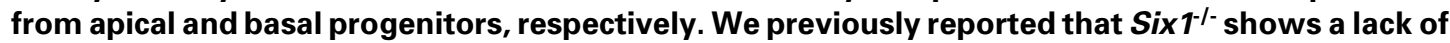
mature ORNs throughout development and disorganization of OE after E12.5. However, the molecular bases for these defects have not been addressed. Here, we show that Six 1 is expressed in both apical and basal progenitors. In Six $1^{/-}$mice, apical proliferating cells were absent and no morphologically identifiable sustentacular cells were observed. Consistently, the expression of Notch2 and Jagged1 in the apical layer was absent in Six ${ }^{-/-}$mice. On the other hand, basal proliferating cells were observed in Six ${ }^{1-1}$ animals, but the expression of $\mathrm{Ngn} 1$, NeuroD, Notch1, and Jagged2 in the basal layer was absent. The expression of Mash1, the determination gene for ORNs, and Hes genes was enhanced in Six ${ }^{1-}$ mice. The present findings suggest that Six 1 regulates production of functional apical and basal progenitors during $O E$ development, through the regulation of various genes, such as neuronal basic helix-loop-helix (bHLH), neuronal repressor bHLH, and genes involved in the Notch signaling pathway.
\end{abstract}

KEY WORDS: six1, olfactory epithelium, basal progenitor, apical progenitor, sustentacular cell

\section{Introduction}

The olfactory system is dedicated to the detection of airborne chemicals called odorants. Odorants interact with olfactory receptors in the olfactory receptor neurons (ORNs) in an epithelial sheet; the olfactory epithelium (OE), which lines part of the nasal cavity. Continuous neurogenesis to produce ORNs is maintained throughout life in the OE (Graziadei and Monti Graziadei, 1979; Schwob, 2002). In mice, the entire population of ORNs is renewed every 4-6 weeks. Because of this naturally occurring regeneration, together with relatively accessible location of $O E$ from the outside, the OE has been regarded as a potential source for generation of new neurons to replace those damaged by injuries or neurodegenerative disorders in the central nervous system (CNS) (Marshall et al., 2006; Lindsay et al., 2010).

In adult rodents, the $\mathrm{OE}$ is a pseudostratified columnar epithelium composed of the apical, middle, and basal layers. In the apical layer, the nuclei and bulk of the soma of sustentacular (supporting) cells are aligned along the nasal cavity. Sustentacular cells are glial-like cells, which possess many glial cell functions (Farbman, 1992). For example, they structurally support ORNs (Nomura et al., 2004), electrically isolate each ORN (Farbman, 1992), and function in a neuroprotective manner through the expression of various enzymes responsible for detoxification (Ding and Coon, 1988; Chen et al., 1992). On the other hand, several layers of ORNs exist in the middle layer. ORNs have a single dendrite that ends with a small knob harboring cilia at the apical side of the OE. Upon stimulation of the olfactory receptors on the cilia by various odorants, impulses are transmitted along

Abbreviations used in this paper: E, embryonic day; GBC, globose basal cell; HBC, horizontal basal cell; OE, olfactory epithelium; OP, olfactory placode; ORN, olfactory receptor neuron; WT, wild type.

\footnotetext{
*Address correspondence to: Kiyoshi Kawakami. Division of Biology, Center for Molecular Medicine, Jichi Medical University, Shimotsuke, Tochigi, 3290498 Japan. Fax: +81-28-544-5476. e-mail: kkawakam@jichi.ac.jp - web: http://www.jichi.ac.jp/biol/home.html
} 
the unmyelinated axons that exit out of the OE on the basal side towards the olfactory bulb in the brain. In the basal layer, there are two morphologically distinct cell types, globose basal cells (GBCs) and horizontal basal cells (HBCs). GBCs are round in shape, mitotically active, and some of them are currently considered basal progenitor cells (Graziadei and Monti Graziadei, 1979; Calof and Chikaraishi, 1989; Caggiano et al., 1994; Schwob et al., 1994; Huard et al., 1998). HBCs are flat in shape and make direct contact with the basal lamina above the underlying lamina propria. HBCs serve as reservoirs of long-lived progenitors and are largely quiescent under normal renewal turnover of ORNs (Carter et al., 2004; Leung et al., 2007; Iwai et al., 2008). The basal progenitor cells continuously generate ORNs and other types of cells throughout life as well as after damage of the OE (Manglapus et al., 2004; Beites et al., 2005).

The process through which the basal progenitor cells give rise to ORNs is called "established neurogenesis". During mouse development, the established neurogenesis begins at embryonic day $(E) 12.5$. Coincidentally and more clearly at E13.5-E14.5, the $\mathrm{OE}$ becomes organized into the mature three-layer structure described above (Beites et al., 2005). Before the established neurogenesis, the olfactory placode (OP)/OE contains thickened olfactory neuroepithelial cells and their cell bodies expand from the apical to the basal side. "Early neurogenesis" or "primary neurogenesis" commences at E10.0 and some cells become neurons in a scattered pattern in the OP/OE (Ikeda et al., 2007). Early neurogenesis gives rise to at least two distinct classes of neurons. One class is the pioneer neurons that migrate out of the OP/OE and localize between OP/OE and the forebrain. The existence of pioneer neurons derived from the OE has been reported in zebrafish and human (Whitlock and Westerfield, 1998; Bystron et al., 2006). Pioneer neurons form "cellular aggregates" at later developmental stage (Schwanzel-Fukuda et al., 1992), which are required for axonal projection of later-born ORNs and for migration of gonadotropin-releasing hormone (GnRH) neurons (Schwanzel-Fukuda et al., 1992; Ikeda et al., 2007). The other class is the early-differentiated neurons whose characteristic and cell fate are currently unknown (lkeda et al., 2007).

Six 1 belongs to the Six-class homeobox gene family homologous to Drosophila sine oculis (Kawakami et al., 2000). Six1 encodes a transcription factor and plays critical roles in the development of sensory organs (Zheng et al., 2003; Ozaki et al., 2004; Ikeda et al., 2007; Chen et al., 2009). We reported previously that Six1 is expressed in the OP and developing OE of mouse. Using Six1 knockout homozygous embryos (Six $1^{-/-}$), we have described the importance of Six1 in early neurogenesis, focusing on the production of pioneer neurons (Ikeda et al., 2007). We also reported the complete absence of OMP expression, which is a marker of mature ORNs, at the later stage of Six $1^{\%} \mathrm{OE}$. Because early and established neurogenesis are considered to be regulated by distinct molecular mechanisms (Beites et al., 2005; Cau et al., 2002), the complete absence of ORNs is not likely to be the direct consequence of defective early neurogenesis in $\mathrm{Six}^{\%}$. In addition, we noticed that the structure of Six $1^{\%}$ OE begins to become disorganized at E12.5, when the stage of early neurogenesis switches to that of established neurogenesis (Ikeda et al., 2007). Therefore, we assume that Six 1 also plays another specific role in established neurogenesis. In the present study, we found that Six 1 is required for the production of apical and basal progenitor cells during established neurogenesis in the embryos, through regulating the expression of genes encoding neuronal transcription factors and genes involved in Notch signaling pathway. The absence of apical progenitors leads to the loss of sustentacular cells, resulting in disorganization of OE structure, and the absence of basal progenitors leads to the loss of ORNs in $\operatorname{Six} 1^{-\%}$.

\section{Results}

\section{Expression of Six1 in proliferating apical and basal cells in established neurogenesis}

The expression domain of Six 1 is confined to the apical and basal layers of OE after E12.5 (Ikeda et al., 2007) and the expression pattern was maintained throughout development to E19 (Fig. 1A). We also analyzed the expression of Six1 by immunohistochemistry using anti-mouse Six1 antibody in the OE of E18.5 fetuses (Fig. 1B) and 1.5-month-old young adult mice (Fig. 1C). Six1-positive signals were observed in the nuclei of sustentacular cells (black arrowheads) and basal cells (red arrowheads) as well as the duct and acinar cells of Bowman's glands (arrows) in the adult. To confirm the cell types that express Six1, we performed co-immunofluorescence in the OE of 2-month-old adult mice (Fig. 1 D-F). In the middle layer of the adult OE, PGP9.5 labeling is reported to be positive in ORNs but negative in Bowman's glands (Weiler and Benali, 2005). We found that Six1positive cells in the middle layer were negative for PGP9.5, indicating that these Six1-positive cells were duct cells of Bowman's glands (Fig. 1D, arrows in OE). The acinar cells of Bowman's glands in the lamina propria (LP) were also Six1-positive (Fig. $1 \mathrm{Db}$, arrow in LP). 5'-bromo-2'-deoxyuridine (BrdU)-positive cells in the basal layer of adult mice correspond to GBCs. We found that BrdU-positive cells were also positive for Six1 (Fig. 1E). Cytokeratin 14 (CK14) labels HBC (Holbrook et al., 1995), and HBCpositive cells were positive for Six1 (Fig. 1F, arrows). These results indicate the expression of Six1 both in GBCs and HBCs. Six1-nuclear staining was also observed in sustentacular and basal cells of one-year-old mice (data not shown).

In the established neurogenesis during development, proliferating cells that are identified by BrdU incorporation during the Sphase are detected in two separate layers, the apical and basal, but not in the middle layer where postmitotic differentiated ORNs reside (Smart, 1971; Cau et al., 2002). Apical proliferating cells are mostly nascent sustentacular cells that are self-renewing, while basal proliferating cells are progenitors for ORNs (Smart, 1971; Beites et al., 2005). Ki67 is another marker for proliferating cells and is expressed throughout the cell cycle (latropoulos and Williams, 1996). Ki67-positive cells were distributed in the apical and basal layers of the OE at E13.5, and were Six1-positive (Fig. 2A). Staining for NeuroD, which labels mitotically active basal progenitor cells (Cau et al., 1997), was noted at that stage (Fig. $2 \mathrm{Bd}$, asterisk). NeuroD-positive cells in the basal region were also Six1-positive (Fig. 2B).

Hes 1 is expressed in the apical progenitor cells during OE development (Cau et al., 2002) and during the production of sustentacular cells after methyl bromide-induced lesions (Manglapus et al., 2004). At E13.5, Six1 and Hes1 were coexpressed in the apical cells (Fig. 2C). At E16.5, Six1 and NeuroD were co-localized in the basal cells (Fig. 2D), consistent with the 
observation at E13.5 (Fig. 2B). In contrast, Six1 was not detected in neurons that expressed terminal-differentiation markers, such as PGP9.5 and OMP (Weiler and Benali, 2005) at E16.5 (Fig. 2 $E, F)$, indicating that the expression of Six1 disappears as they differentiate into ORNs. SUS-4 is a marker of mature sustentacular cells and resides in the apical surface of the cytoplasm of adult OE (Goldstein and Schwob, 1996; Fig. 2Gd, double asterisks). The majority of SUS-4-positive cells were Six1-positive in the adult (Fig. 2G). It was also noted that Ki67-positive apical cells, which correspond to proliferating sustentacular cells in the adult OE (Weiler and Farbman, 1998), were Six1-positive, although they were small in number (Fig. $2 \mathrm{H}$, arrow). Furthermore, Ki67positive basal cells that correspond to GBC were Six1-positive in the adult $\mathrm{OE}$ (Fig. $2 \mathrm{H}$, arrowhead). These results indicate that Six 1 is expressed in the apical and basal proliferating cells, which correspond to sustentacular and basal cells, respectively, during established neurogenesis as well as in the adult.

\section{Absence of apical progenitors in Six $1^{-/}$}

Six $1 \%$ shows disorganization of OE, which starts at around E12.5 (Ikeda et al., 2007). At this stage, established neurogenesis begins in the developing OE. BrdU-positive cells were observed in both the apical and basal layers in WT at E12.5 and E13.5 (Fig. $3 A, C)$. Strikingly, no such cells were detected in the apical layer of Six 1/- OE at E12.5 and E13.5 (Fig. 3 B,D), indicating absence of apical proliferating cells in Six $1^{--}$. In contrast, BrdU-positive cells were preserved in the basal layer at E12.5 and E13.5 in Six $1^{-/-}$OE (Fig. 3 B,D). This finding was in sharp contrast to that of Mash $1^{1 /-}$, in which BrdU-positive cells were reduced in number in the basal layer but present throughout the apical-basal extent of the epithelium (see Fig. 7 A,B) (Cau et al., 2002; Murray et al., 2003). At E16.5, BrdU-positive cells were noted in both apical and basal layers in WT (Fig. 3E). In Six 1/-, this stage of development was characterized by marked disorganization of OE, ill-defined structure of the OE, presence of BrdU-positive cells scattered in the mass of the nasal cavity (Fig. 3F). It is noteworthy that the

Fig. 1. Expression patterns of Six 1 in the olfactory epithelium (OE) of the fetus and adult mouse. (A) In situ hybridization for Six 1 at embryonic day (E) 19. (a) Dorsal part of the nasal cavity. Six1 is expressed strongly in the apical side of OE with scattered pattern in the basal side, as well as in mesenchyme underlying OE. (b) Ventral part of the nasal cavity. Six1 expression is observed in the apical layer of the epithelium of vomeronasal organ (VNO). (B,C) Immunohistochemistry using anti-mouse Six1 antibody in the OE of (B) E18.5 fetus and (C) young adult (1.5-month-old), followed by counterstaining with hematoxylin. Lamina propria (LP) underlying OE is also positive for Six1. Note Six1 immunostaining in nuclei of sustentacular cells (black arrowheads) and those of basal cells (red arrowheads), and in nuclei of the Bowman's gland duct/acinar cells (arrows). (D-F) Immunofluorescence in 2-month-old adult OE using antibodies to Six1 (red) and (D) PGP9.5 (green), (E) 5'-bromo-2'deoxyuridine (BrdU) (green), and (F) Cytokeratin 14 (CK14). Arrows in (D) inside OE indicate nuclei of duct cells and those in LP indicate acinar cells of Bowman's glands. In (E), BrdU incorporated cells are GBC in the adult $O E$ and they are Six1-positive. Arrows in (F) in the basal compartment are CK14-positive HBC that are Six1-positive. Scale bars, $400 \mu \mathrm{m}(\mathrm{A}), 100 \mu \mathrm{m}$ $(B-E)$, and $50 \mu \mathrm{m}(F)$. The white broken line demarcates the OE from the underlying mesenchyme. $O B$, olfactory bulb; $O E$, olfactory epithelium; $R E$, respiratory epithelium; NC, nasal cavity; NS, nasal septum; VNO, vomeronasal organ; $L P$, lamina propria. respiratory epithelium (RE) was relatively preserved in Six $1^{1--}$.

The Notch signaling pathway is an important regulator in $\mathrm{OE}$ development and multiple Notch receptors, Notch ligands, Notch effectors, and a Notch modulator are expressed in the developing OE (Lindsell et al., 1996; Cau et al., 2000, 2002; Mitsiadis et al., 2001; Carson et al., 2006; Schwarting et al., 2007; Rodriguez et al., 2008). Notch2 is expressed in the apical layer of embryonic OE (Carson et al., 2006). The Notch ligand gene Jagged1 (Serrate1) and Notch effector gene Hes 1 are also expressed in the apical progenitors in a Mash1-dependent manner at E12.5 (Cau et al., 2002). To examine whether the components of Notch signaling pathway are preserved in the apical layer of Six $1^{-/-} \mathrm{OE}$, we compared the expression of Notch2, Jagged1, and Hes1
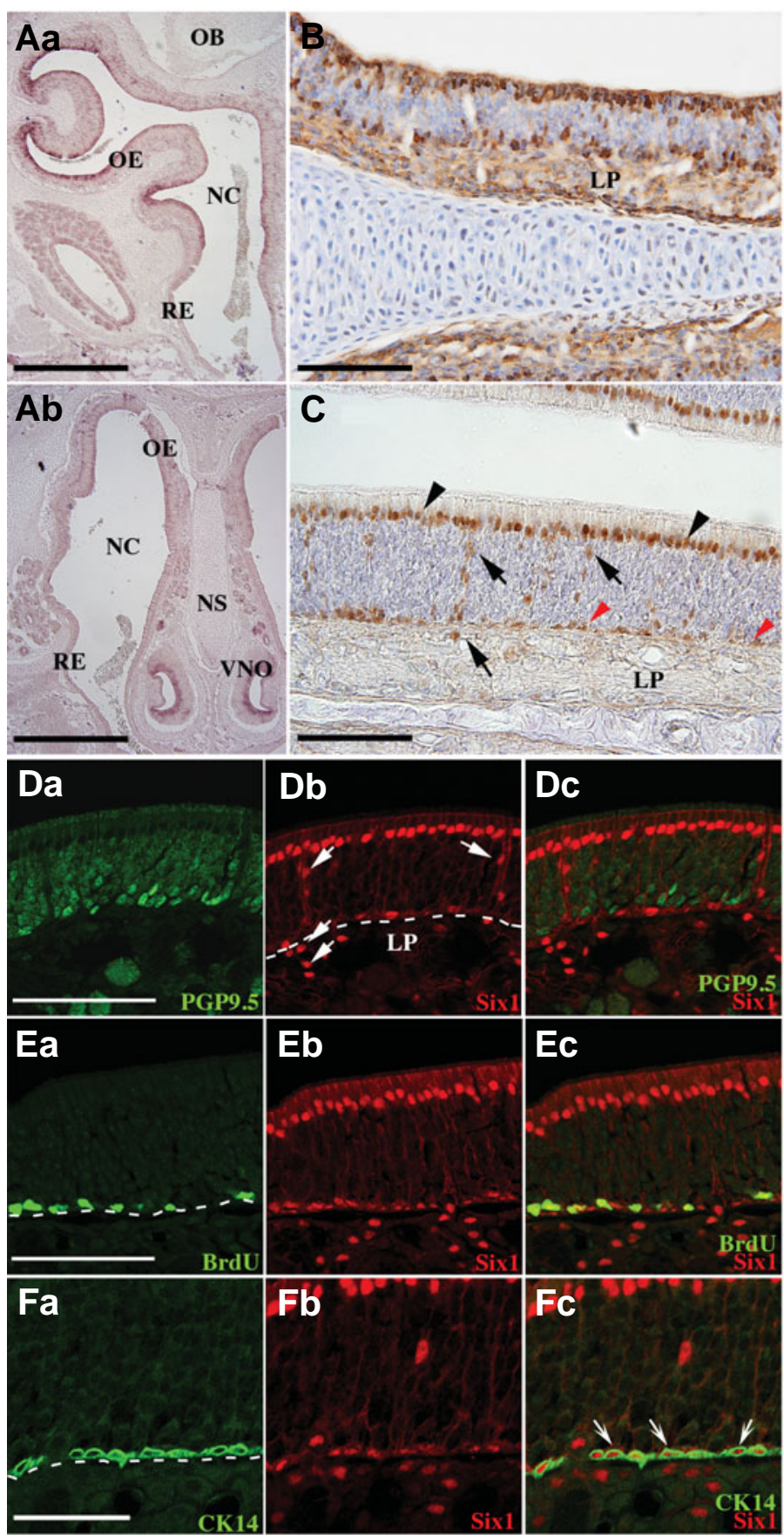


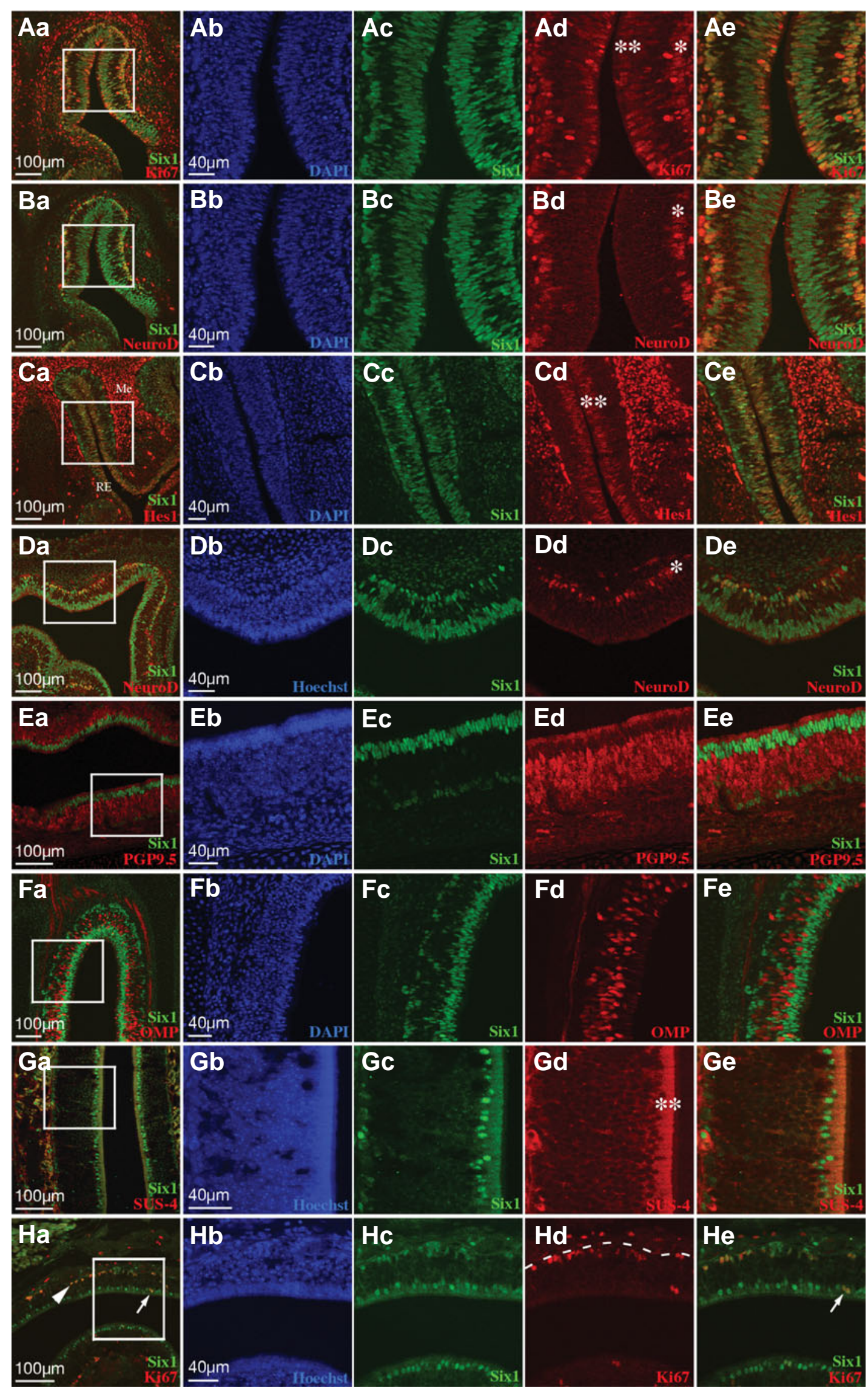

Fig. 2. Expression of Six 1 and other marker proteins in the developing OE. Immunofluorescence of OE using antibodies to Six 1 (green) and to various marker proteins (red). Nuclei are stained with 4,6diamidino-2-phenylindole (DAPI) (A,B,C,E,F) or Hoechst 33258 (Hoechst) (D,G,H) and appear blue in color in $\mathbf{b}$. Higher magnifications of the white boxed regions in panel a are shown in panels b-e. Merged figures of Six 1 and marker proteins are shown in panels a and e. (A) Six1-positive cells in the apical layer (double asterisks) and basal layer (asterisk) are Ki67-positive, indicating that these cells are proliferating apical and basal cells at E13.5. (B) NeuroD-positive cells in the basal layer lasterisk) are Six1-positive at E13.5. Since sections $(A, B)$ are identical, we confirmed that NeuroDpositive cells are positive for Ki67. (C) Hes1-positive apical cells in the OE (double asterisks) are Six1-positive at E13.5. Strong Hes1-positive cells are observed in the future respiratory epithelium (RE) and the mesenchyme surrounding $O E$ (Me), in which Six 1 express at moderate low level. (D) NeuroD-positive cells in the basal layer (asterisk) are Six1positive at E16.5. (E) PGP9.5 is a marker of olfactory receptor neurons (ORN). ORN are Six1negative at E16.5. (F) Another marker of ORN is OMP, which is also Six1-negative at E16.5. (G) SUS-4 is a marker of sustentacular cells, and is positive in apical cell cytoplasm of OE (double asterisks) in 1.5-monthold young adult mouse. Nuclei of apical cells are positive for Six 1 , indicating that Six 1 is expressed in sustentacular cells. (H) Ki67-positive cells are observed in GBCs in the basal layer (arrowhead) and in sustentacular cells in the apical layer (arrow), although the latter are small in number in OE of 1.5month-old young adult mouse. Both of them are positive for Six1. The white broken line in (H) demarcates the OE from the underlying mesenchyme. RE, respiratoryepithelium; Me, mesenchyme. 
Fig. 3. 5'-bromo-2'-deoxyuridine (BrdU) incorporation in OE cells of WT and Six 1\%. Immunohistochemistry for BrdU (brown nuclei) after 1 hour of BrdU incorporation, followed by hematoxylin staining. BrdUpositive cells are observed in two separate regions, apical and basal, at E12.5, E13.5, and E16.5 of WT OE (A,C,E). E12.5 is a transition stage, when BrdU-positive cells can be observed throughout OE or in two separate layers, depending on the region. Note the absence of apical BrdU-positive cells at E12.5, E13.5, and E16.5 in Six1\% (B,D,F). Disorganization of OE starts at E12.5 and becomes apparent at E13.5 in Six $1 \%$ (arrows). Due to the severe disorganization, the OE is not identified at E16.5 in Six $1 \%$, while RE is relatively preserved (F). Right side is dorsal side and upper side is medial in the panels of E12.5 and E13.5. Scale bars, $200 \mu \mathrm{m}(A, B), 100 \mu \mathrm{m}(C, D)$, and $400 \mu \mathrm{m}(E, F)$. VNO, vomeronasal organ, $O E$, olfactory epithelium; $N S$, nasal septum; $R E$, respiratory epithelium.

between WT and Six 1/- by in situhybridization. The expression of Notch2 was observed in the apical layer of OE in WT (Fig. 4A), but was absent in Six1/- at E12.5 (Fig. 4B), as well as at E13.5 (data not shown). The expression of Jagged1 was weak in the apical layer and strong in the apical layer at the mediocaudal part of OE in WT (Fig. 4C), but absent in Six1/- (Fig. 4D). These results indicated the lack of apical proliferating progenitors and components of Notch signaling pathway in the developing OE of Six $1^{-1-}$. In contrast, Hes1 showed enhanced expression in Six $1^{-1-}$ compared with WT. The expression domain of Hes1 was markedly expanded throughout the apical-basal layers in the OE of Six1/-, compared with that of WT (Fig. 4 E,F).

Cytokeratin 18 (CK18) is an intermediate filament protein and a marker of sustentacular cells and Bowman's gland cells in adult mice and at E18.5 (Fig. 4G) (Suzuki and Takeda, 1991; Holbrook et al., 1995; Williams et al., 2004). Immunohistochemistry using anti-CK18 antibody at E18.5 showed markedly reduced signals in the disorganized mass in Six $1^{-/}$nasal cavity (Fig. $4 \mathrm{H}$ ), indicating the absence of structurally identified sustentacular cells in Six $1^{-1-}$

\section{Defective basal progenitor cells in Six $1^{-/}$}

The sequential cascade of neuronal basic helix-loop-helix (bHLH) transcription factors, Mash1, Ngn1, and NeuroD, is known to be responsible for progression of neurogenic differentiation and cell proliferation during established neurogenesis (Cau et al., 1997, 2002; Gordon et al., 1995; Calof et al., 2002). The Mash1positive progenitor cell gives rise to the transit amplifying progenitor cell that expresses $\mathrm{Ngn} 1$, and in turn NeuroD. Phd 1 is a pairedhomeobox gene known to be expressed in basal progenitor cells, depending on the expression of Ngn1 in OE development (Cau et al., 2002). Ebf1 and Lhx2 are the HLH and LIM-homeobox genes, respectively, and both genes are expressed in the basal progenitor cells independent of $\mathrm{Ngn} 1$ expression, but dependent on that

Fig. 4. Expression of genes of the Notch signaling pathway and sustentacular cell marker protein in WT and Six $\mathbf{1}^{\%}$. (A-F) In situ hybridization of WT and Six $1 \%$ at E12.5 using riboprobes for Notch2, Jagged1, and Hes1. In the WT, the expressions of Notch2 and Hes1 are found largely on the apical side and that of Jagged1 on the apical side weakly. The expression of Notch2 and Jagged1 is absent in the OE of $\mathrm{Six}_{1} \%$. The expression of Hes 1 is enhanced in the OE of Six $1 \%$. Right side is dorsal side and upper side is medial side. The broken line demarcates the OE from the underlying mesenchyme. $(\mathbf{G}, \mathbf{H})$ Immunohistochemistry (IHC) using anti-cytokeratin 18 (CK18) antibody at E18.5. In Six1\%, disorganized mass of OE is faintly stained for CK18. Scale bars, $100 \mu \mathrm{m}$. NS, nasal septum; NC, nasal cavity.
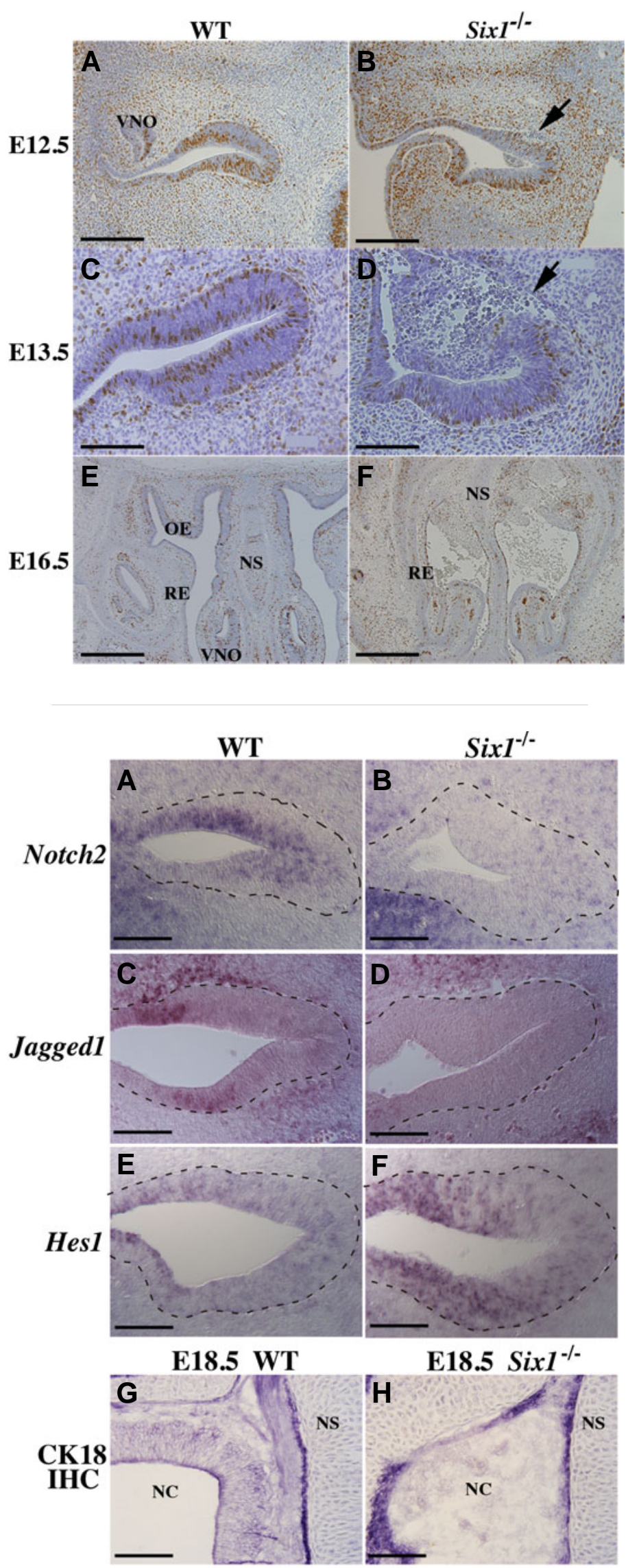
of Mash1 in the developing OE (Cau et al., 2002). Because BrdUpositive cells were observed in the basal layer of Six $1^{-/-}$at E12.5 and E13.5 (Fig. 3 B,D), it was expected that basal progenitors that produce ORNs were present in Six $1^{-/-}$. To determine whether the

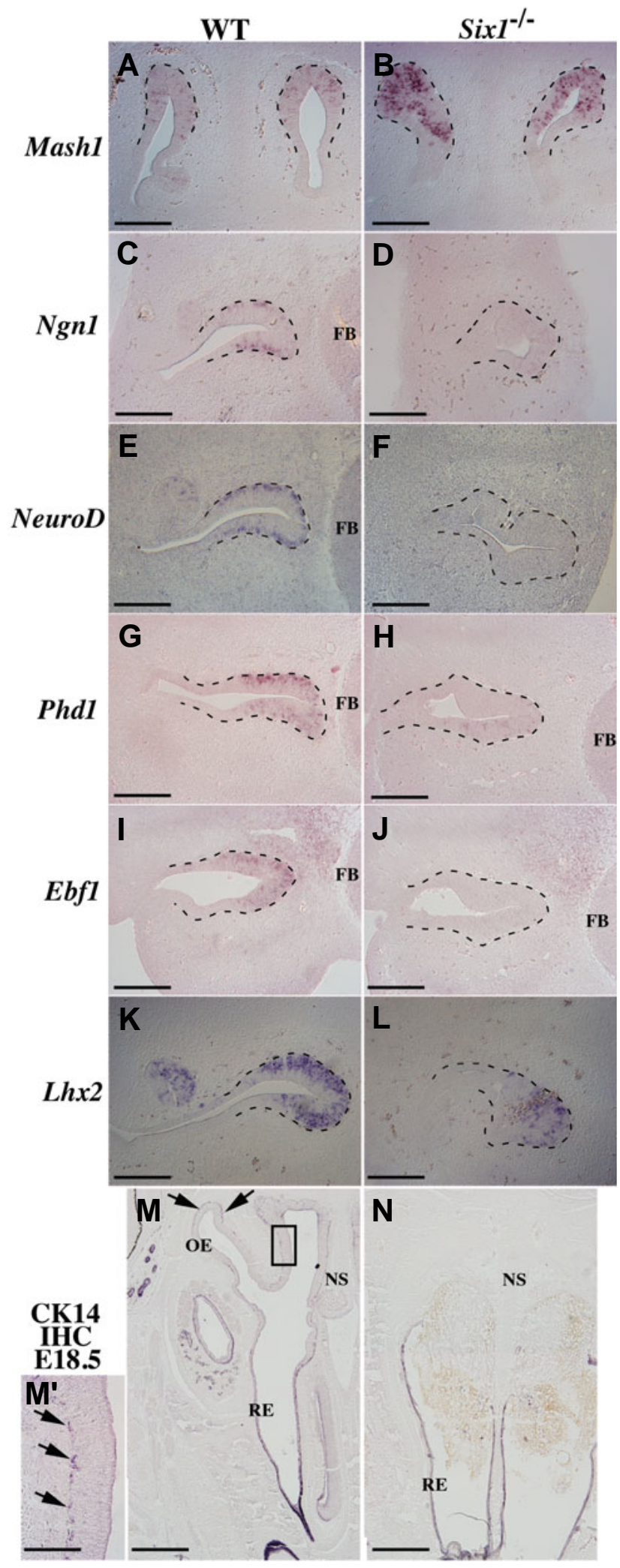

proliferating cells in the basal layer in Six $1^{-/-}$were neural progenitor cells, we first examined the expression of Mash1. Expression of Mash1 was increased and the expression domain was enlarged in Six $1^{-/-}$compared with WT OE (Fig. 5 A,B). In contrast, the expressions of downstream target genes of Mash1, such as Ngn1 and Phd1, were markedly reduced, and that of NeuroD was almost completely absent in Six $1^{-/-}$(Fig. 5 D,F,H). The expression of Ebf1 was noticeably reduced and that of $L h x 2$ was decreased in $\mathrm{Six}^{1 /-}$, although the latter was relatively preserved (Fig. $5 \mathrm{~J}, \mathrm{~L}$ ). These results indicate that although Mash1-expressing progenitors were produced in Six $1^{-/}$, they did not progress to differentiate into transit Ngn1-expressing progenitor cells and lost the ability to produce neurons destined to ORNs.

We also performed immunohistochemistry using anti-CK14 antibody at E18.5. The CK14 labels HBCs (see Fig. 1F) and RE in adult mice (Holbrook et al., 1995), and in E18.5 WT fetus (Fig. $\left.5 \mathrm{M}, \mathrm{M}^{\prime}\right)$. As shown in Fig. 5N, CK14 was not observed in the basal layer of OE in Six $1^{-/-}$, but was expressed in RE. This observation indicates the absence of HBCs in Six $1^{-/-}$at later stage of development.

Notch1 is expressed in the basal layer at E12.5-E13.5 (Fig. 6A) (Mitsiadis et al., 2001; Schwarting et al., 2007) and strongly in the future RE at E11.0 (Schwarting et al., 2007). It is suggested that Notch1-mediated signals function to maintain a neurogenic progenitor pool at the stage of established neurogenesis during development (Schwarting et al., 2007). In situ hybridization was performed to determine the expression status of Notch1 in the basal layer in Six $1^{-1-}$. The expression of Notch1 in the OE was lost, although it was present in the future RE region in Six 1/- (Fig. 6B and data not shown). Furthermore, a Notch ligand Jagged2 (Serrate2) and a modulator of Notch signaling Lunatic fringe ( $L f n g$ ) were expressed in the basal region of WT OE (Fig. 6 C,E), but absent in Six 1/- OE (Fig. 6 D,F). These results indicate the absence of some of the components of Notch signaling pathway in the basal proliferating cells of Six $1^{-1-}$. In contrast, enhanced expression of Notch effecter gene Hes5 was noted, together with a wider distribution to the more apical side in $\operatorname{Six}^{-/-}$(Fig. $6 \mathrm{G}, \mathrm{H}$ ).

\section{Expression of Notch1 and Notch2 in Mash1/-}

Mash1, the key determinant gene for ORN differentiation, is also known to be required for the expression of the Notch signaling genes, such as Jagged1, Jagged2, Hes1, and Hes5 (Cau et al., 2002). Absent or underexpression of these genes is reported in Mash1-/- (Cau et al., 2002). Examination of Notch1 and

Fig. 5. Defects of neurogenesis in Six 1\% OE. (A-L) In situ hybridization of WT and Six $1 \%$ at E12.5 with riboprobes for Mash1, Ngn1, NeuroD, Phd1, Ebf1, and Lhx2. (A,B) Enhanced expression of Mash1 in Six1\%OE. (C,D) Marked reduction of Ngn 1 expression in Six $1^{\%}$ OE. (E,F) Complete lack of NeuroD expression in Six1\% OE. (G-J) Marked reduction of Phd1 and Ebf1 expression in Six1\% OE. $(\mathbf{K}, \mathbf{L})$ Decreased expression of $\mathrm{Lh} \times 2$ in Six $1 \% O E .\left(\mathbf{M}, \mathbf{M}^{\prime}, \mathbf{N}\right)$ Immunohistochemistry $(I H C)$ using anti- CK14 antibody at E18.5. The basal margins of OE and RE are positive for CK14 in WT. In Six 1\%, RE is positive for CK14. (M') is a magnification of the boxed region in (M). In the basal layer of OE, HBCs are labeled by anti-CK14 antibody. Arrows in $\left(M, M^{\prime}\right)$ indicate signals in horizontal basal cells. Right side is dorsal side and upper side is medial side in panels (C- L). Scale bars, $200 \mu \mathrm{m}(A-L), 400 \mu \mathrm{m}(\mathrm{M}, N)$, and $100 \mu \mathrm{m}\left(\mathrm{M}^{\prime}\right)$. The broken line demarcates the $O E$ from the underlying mesenchyme. FB, forebrain; $O E$, olfactory epithelium; $R E$, respiratory epithelium; NS, nasal septum. 
Notch2 expression in Mash1\% at E13.5 showed Notch1 expression in the basal layers of WT, but not in Mash1/- (Fig. 7D; Tietjen et al., 2003). This observation correlated with the absence of BrdU-positive cells in the basal layer of Mash1/- OE (Fig. 7B; Cau et al., 2002; Murray et al., 2003). Notch2 was expressed in the apical layer, although it was weaker than that of the WT (Fig. 7 E,F). To determine the hierarchy of Mash1 and Six1, we analyzed the expression of Six1, and found that it was almost similar in WT and'Mash1/- at E13.5 (Fig. 7 G,H; Tietjen et al., 2003), as we observed at E11.5 (Ikeda et al., 2007). Based on these results, we conclude that, 1) The expression of Six1 is not dependent on Mash1, 2) The expression of Notch1 in the basal layer is dependent on both Six1 and Mash1, 3) The expression of Notch2 in the apical layer is dependent on Six1, and partially on Mash1.

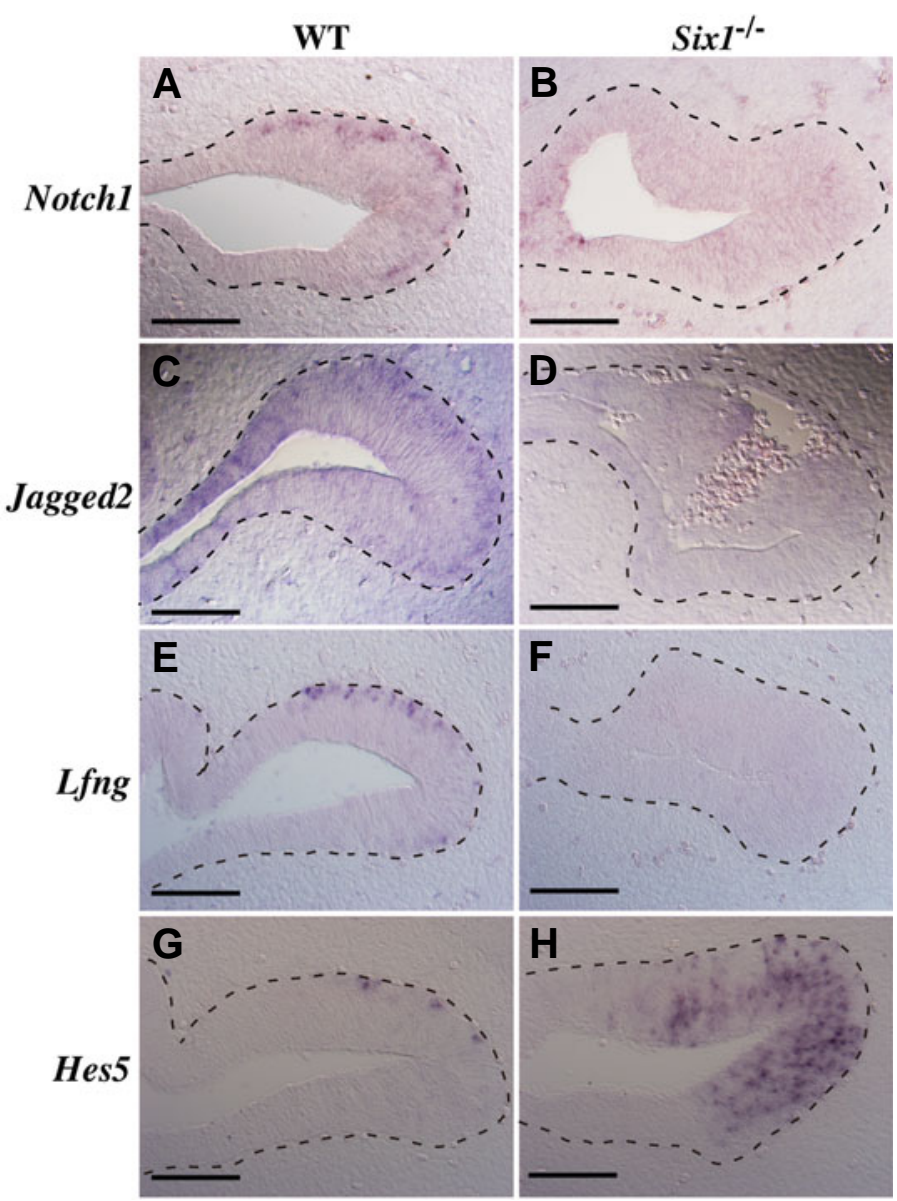

\section{Discussion}

\section{Six1 plays an important role in established neurogenesis through production of basal and apical progenitor cells in the developing $O E$}

Two modes of neurogenesis exist during development in the $\mathrm{OE}$; early neurogenesis and established neurogenesis. These two processes are quite different and the difference cannot be recognized only by the developmental stage. 1) The origin and distribution of neurons are different. In the early neurogenesis, all OP/OE cells proliferate continuously and some undergo differentiation into TuJ1-positive neurons in a scattered pattern (Ikeda et al., 2007). In the established neurogenesis, the proliferating cells separate into apical and basal layers. Only the basal cells un-

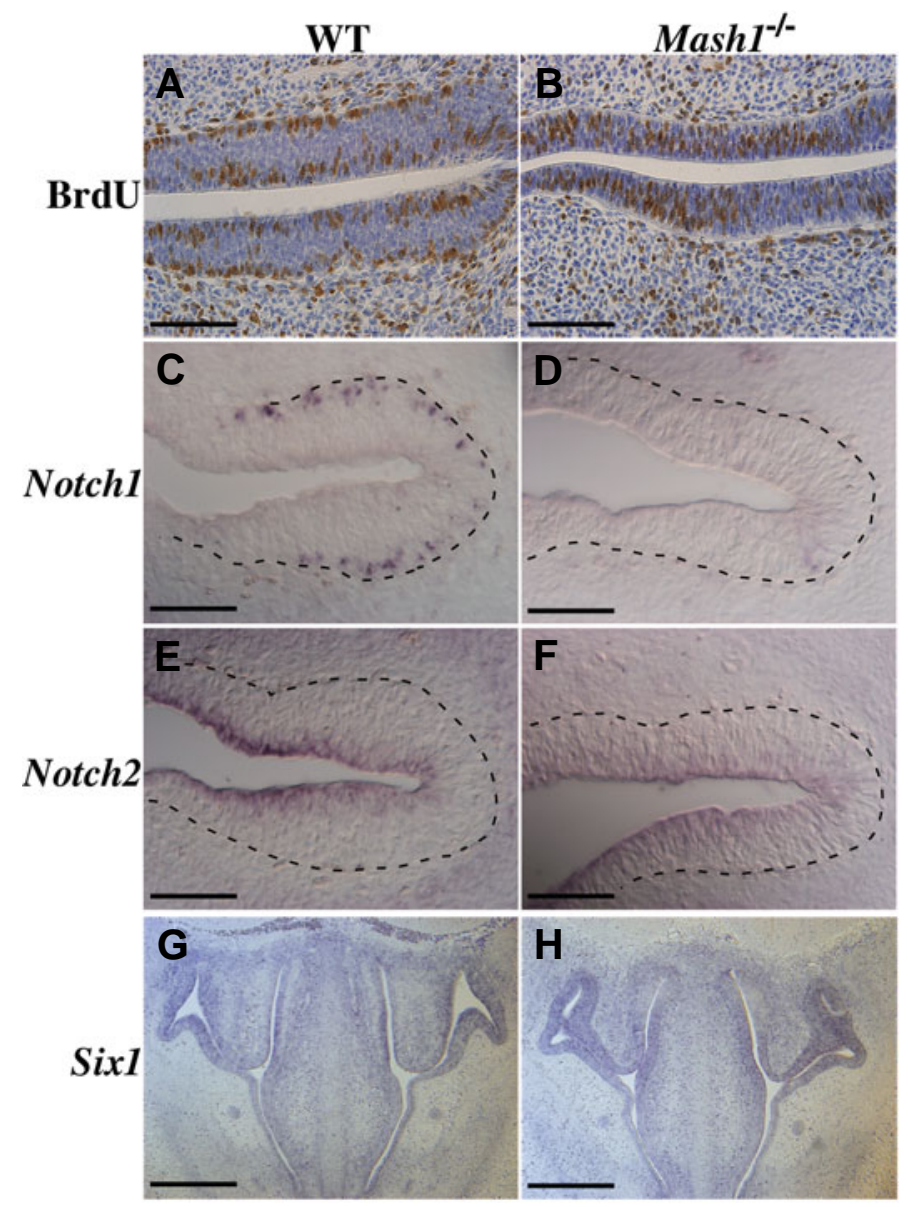

Fig. 6 (Left). Expression of genes of the Notch signaling pathway in WT and Six $\%$. (A-H) In situ hybridization of WT and Six $1 \%$ at $E 12.5$ using riboprobes for Notch1, Jagged2, Lfng, and Hes5. (A-D) Notch1 and Jagged2 are expressed in the basal layer in WT. The expression of these genes in the OE is absent in Six $1 \%$. (E,F) Notch signaling modulator Lfng is expressed in the basal layer in WT, but is absent in Six $1 \%$. (G,H) Hes5 is expressed in the OE basal layer in WT. Higher expression is observed in Six $1 \%$. Right side is dorsal side and upper side is medial side. The broken line demarcates the OE from the underlying mesenchyme. Scale bars, $100 \mu \mathrm{m}$.

Fig. 7 (Right). Analysis of Mash1\% OE. (A,B) BrdU incorporation in OE cells of WT and Mash1\% at E13.5. Immunohistochemistry for BrdU (brown nuclei) after 1 hour of BrdU incorporation, followed by hematoxylin staining. BrdU-positive cells are observed in two separate regions, the apical and basal in WT. BrdU-positive cells are missing in the basal layer and sparse in the apical layer in Mash $1 \%$. The epithelium is thinner in Mash $1 \%$ compared with that of WT. (C-H) In situ hybridization of WT and Mash1\% at E13.5 using riboprobes for Notch1, Notch2, and Six1. The expression of Notch1 in the basal layer is absent and that of Notch2 in the apical layer is reduced in Mash $1 \%$. The expression of Six1 is similar in WT and Mash $1 \%$. Scale bars, $100 \mu \mathrm{m}(\mathrm{A}-\mathrm{F})$ and $400 \mu \mathrm{m}(\mathrm{G}, H)$. The right is the dorsal and the upper is the medial side in panels (C-F). The broken line demarcates the OE from the underlying mesenchyme. 
dergo neuronal differentiation and neurons reside in the middle layer. 2) Distinct types of neurons are produced. In the early neurogenesis, pioneer neurons and other uncharacterized neurons are produced. On the other hand, ORNs are produced in the established neurogenesis. Reflecting the difference in neurogeneses, various gene knockout mice with defective OE neurogenesis mostly show defects in the established neurogenesis without any defects in the early neurogenesis. Therefore, it has been considered that the regulatory mechanism that governs and genes involved in the two processes are different. In this context, the Six $1^{-/}$mouse is the first knockout strain with defective early neurogenesis (Ikeda et al., 2007). One of the main findings of the present study is that Six 1 also plays an important role in the established neurogenesis during OE development, as evidenced by the absence of functional apical and basal progenitors in Six 1 - mice.

With regard to the basal progenitors, the expression of Mash1 in a subpopulation of Six1-positive OE cells makes it competent to neuronal lineage. The distribution of Mash1-positive neuronal progenitors is progressively limited to the basal layer. Then, the Mash1-positive progenitors give rise to the transit amplifying Ngn1-positive progenitors, which settle on the basal side of OE. The Ngn1-positive progenitors, in turn, give rise to NeuroDpositive neuronal precursors. The differentiation gene NeuroD is expressed in these Ngn1-positive basal progenitors during the transition from proliferation to differentiation, i.e., fully-differentiated ORNs (Cau et al., 1997, 2002). Six1 was expressed in Mash1-, Ngn1-, and NeuroD-positive progenitors/precursors (Fig. 2, 8; data not shown), and its expression disappeared with the differentiation of the progenitors into ORNs (Fig. 2). Although BrdU-positive proliferating cells were present in the basal layer and Mash1-positive cells were observed throughout OE in Six1 1-, the expression of Ngn1, NeuroD, and other neural marker genes, such as Phd1, Ebf1, and Lhx2, was absent or reduced at

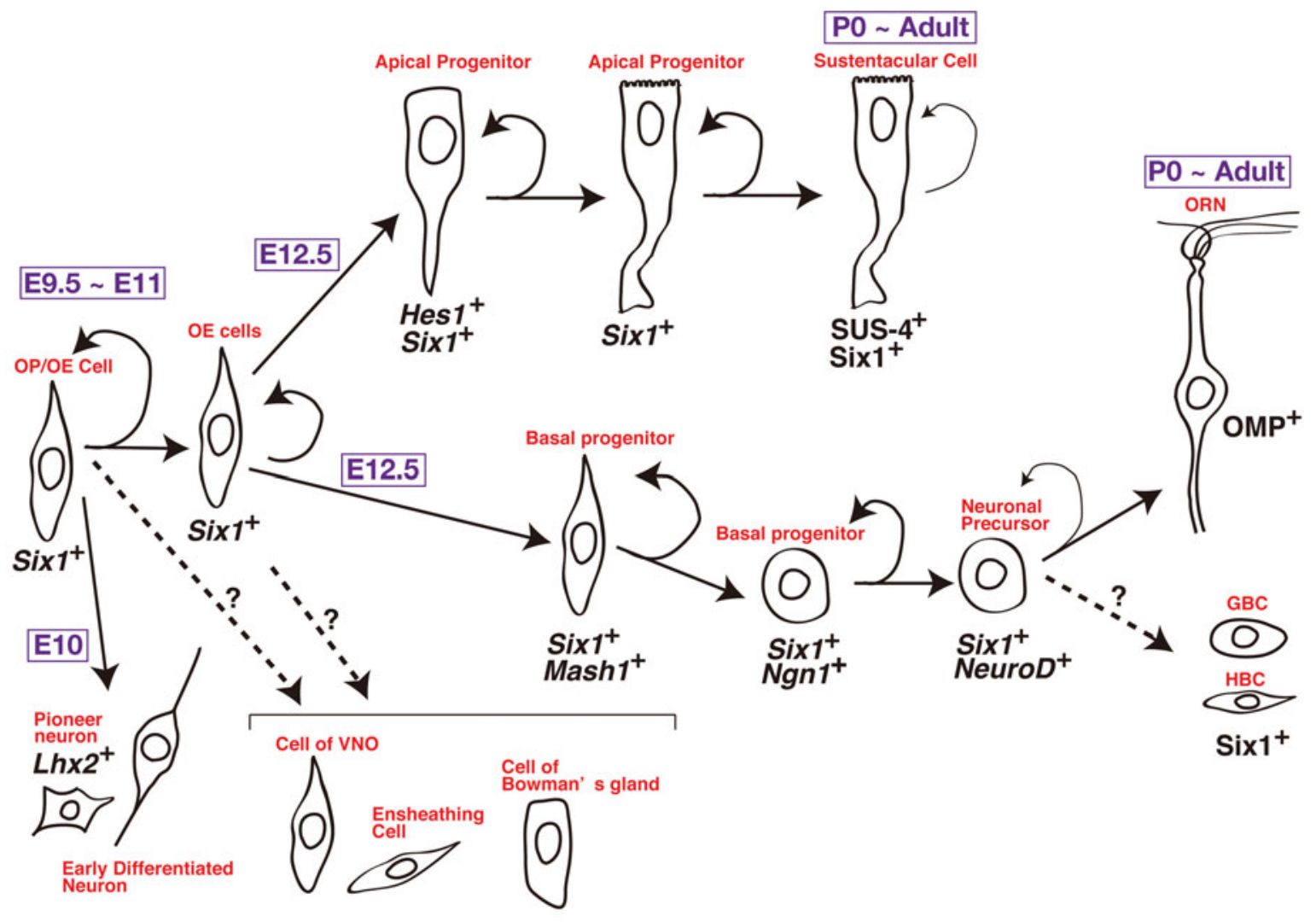

Fig. 8. Six 1 is essential for production of both functional apical and basal progenitors. Simplified scheme of developmental differentiation from olfactory placpde (OP)/OE cells to ORNs and sustentacular cells. At E9.5 mouse embryo, all epithelial cells are positive for Six 1 and undergo robust proliferation. At E10.0, some of them differentiate into neurons (early neurogenesis), a process in which Six1 plays a key role (Ikeda et al., 2007). Pioneer neurons migrating out of OE are positive for Lhx2, but negative for Six1 (Ikeda et al., 2007). Epithelial cells in the developing OE continue to proliferate and retain the potency to differentiate into different cell types, such as cells of VNO, cells of Bowman's gland, olfactory ensheathing cells (although their origin is currently debated), neurons, and glial-like sustentacular cells. In other word, they are multipotent OE cells. These OE cells are positive for Six1. At E12.5, basal and apical progenitors are identified, and both are Six1-positive (see Fig. 2 A, B). (Lower part) A subpopulation of the OE cells becomes Mash1-positvive neuronal progenitors and they are progressively restricted to reside in the basal layers. The Mash1-positive progenitors give rise to the transit amplifying Ngn1-positive progenitors, which in turn give rise to NeuroD-positive neuronal precursors. They divide at least once (thin arrow) and produce ORNs. The expression of Six 1 is downregulated during differentiation from NeuroD-positive progenitors into ORN. It is not clear whether NeuroD-positive basal progenitors during development directly become GBC and/or HBC in the OE of postnatal and adult mice. (Upper part) A subpopulation of the OE cells that are Six1-positvive but Mash1-negative becomes apical progenitors, which are positive for Hes1. They are self-renewing progenitors of sustentacular cells. In the adult, some of the sustentacular cells may divide through the self-renewing process (see Fig. 2H), although they are small in number (thin arrow). 
E12.5 (Fig. 5). Moreover, we reported previously the complete absence of OMP-positive cells throughout development in Six ${ }^{1 /-}$ (Ikeda et al., 2007). These findings indicate the absence of bona fide basal progenitors that produce ORNs in Six $1^{-1}$. We conclude that Six1 plays an important role in the production of functional basal progenitors independent of Mash1, and in neuronal differentiation of basal progenitors, partly by regulating the expression of Ngn1 and NeuroD during established neurogenesis.

In contrast to neuronal lineage, little is known about the gene cascade for sustentacular cell differentiation. Based on the present study, we suggest the following scenario: At E12.5-E13.5, Mash1negative apical proliferating cells emerge from Six1-positive $\mathrm{OE}$ cells. These cells are Six 1 - and Hes1-positive and self-renewing apical progenitors for sustentacular cells (Fig. 2, 8; Beites et al., 2005; Cau et al., 2002). Six $1^{-/-}$lack apical proliferating cells from the onset of established neurogenesis and are also deficient in morphologically recognizable sustentacular cells at later embryonic developmental stage (Fig. 4H). The disruption of the epithelial structure of OE in Six $1^{-1-}$ is probably due to the absence of sustentacular cells, because sustentacular cells are essential for proper ORN configuration (Nomura et al., 2004). Compared with other gene knockout mice with defective OE development (reviewed in Nicolay et al., 2006), Six $1^{-1-}$ is unique as it exhibits totally disorganized $\mathrm{OE}$ together with the absence of sustentacular cell population, emphasizing the role of Six 1 in epithelial integration through the production of sustentacular cells.

It was reported recently that persistent expression of Notch2 is required for maintaining sustentacular cell function in the $O E$ of adult mouse (Rodriguez et al., 2008). Conditional null mutant adult mouse of Notch2 showed disruption of the OE laminar organization and underexpression of sustentacular cell marker genes (Rodriguez et al., 2008). Considering the facts that Six 1 is expressed in the apical layer in adult mice and that the expression of Notch2 was absent in the apical layer in Six $1^{-1-}$, Six 1 may also play a role in the maintenance of sustentacular cells through direct or indirect regulation of Notch2 expression.

The low rate of proliferation of sustentacular cells has been proposed to indicate their slow turnover and self-replacement, and catching-up on the slow growth of OE in rodents (Graziadei and Monti Graziadei, 1979;Weiler and Farbman, 1998). Our results showed that Ki67-positive cells in the adult OE are Six1positive (Fig. 2G). Since Six 1 is known to regulate cell proliferation (Christensen et al., 2008), it is possible that Six1 provides the stimulus for sustentacular cell proliferation in the adult OE under physiological condition (Fig. 8). This hypothesis will be examined in the future using sustentacular cell-specific conditional knockout mice of Six 1 .

\section{Notch signaling pathway in established neurogenesis}

Notch signaling pathway is known to be a central regulator of cell fate in the developing CNS (Yoon and Gaiano, 2005; Corbin et al., 2008; Lathia et al., 2008). For example, it functions 1) to maintain stem/progenitor cells during embryonic development and postnatally (Solecki et al., 2001; Hitoshi et al., 2002), 2) to inhibit neural differentiation (de la Pompa et al., 1997; Ohtsuka et al., 1999), 3) to promote glial-precursor formation (Gaiano et al., 2000), and 4) to determine glial-cell fate (Tanigaki et al., 2001). In a manner analogous to the developing CNS, the expression of Notch 1 in the basal cells is considered important for their maintenance as progenitor cells (Schwarting et al., 2007). Because BrdU-positive basal cells were preserved in Six $1^{-1-}$, Notch1 seems to mainly maintain the differentiation potential, rather than the proliferation activity in the basal progenitors. On the other hand, the expression of Notch2 in the apical cell layer of OE may be essential for cell fate determination of glial-like sustentacular cells and amplifying their cell number. In this context, it is reasonable to assume that the lack of expression of Notch1 and Notch2 results in deficiency of basal progenitors, apical progenitors, and sustentacular cells in Six $1^{-1}$.

There is a general agreement that Hes genes are the downstream targets of Notch signaling (Jarriault et al., 1995, 1998; Shimizu et al., 2002). However, it has also been shown that the expression of Notch 1 is negatively regulated by Notch1-independent Hes genes at early stage and that the initiation of Notch1 expression is one of the key features for switching from symmetric to asymmetric cell division, which produces various cell types in the developing CNS (Hatakeyama and Kageyama, 2006). In Six $1^{1-1}$, enhanced expression of Hes genes was observed at $\mathrm{E} 10.5$, before the stage of established neurogenesis (lkeda et al., 2007) and it was sustained at later stages (Fig. 4,6). Therefore, Notch genes may be persistently repressed by the enhanced expression of Hes genes in Six $1^{--}$OE (see below).

\section{Gene cascade involved in differentiation during the estab- lished neurogenesis}

The present study defined the role of Six 1 in the multistep process of production of apical and basal progenitors in the later developing OE. First, Six1 regulates the expression of neuronal repressor genes; Hes 1 and Hes5, to moderate levels and limits their expression domains to the apical and basal layers, respectively. This observation is consistent with our previous findings of increased expression of Hes 1 and Hes5 at E10.5 in Six $1^{-1-}$ and that Six 1 represses their expression in cultured cells (Ikeda et al., 2007). Second, Six 1 activates the expression of neural bHLH transcription factors, such as Ngn1 and NeuroD, as we observed in the early neurogenesis (lkeda et al., 2007). Third, Six1 activates the expressions of Notch2 and Notch 1 in apical and basal layers, respectively. Consistent with this schema, a recent study suggested that Six 1 acts upstream of Notch signaling in early sensory patch development in the inner ears of heterozygous Catweasel mice harboring a point mutation in the Six1 gene (Bosman et al., 2009).

In Six $1^{-\%}$, overexpression of Hes 1 and Hes5 may inhibit neurogenesis by blocking the expression of Ngn1, in a manner analogous to the CNS (Kageyama and Nakanishi, 1997; Cau et al., 2000). In addition, the lack of activation of Ngn1 and NeuroD in Six 1/- results in defective differentiation into ORNs. Furthermore, though not mutually exclusive, the lack of expression of Notch genes may result in dysregulation of asymmetric cell division followed by defective formation of heterogeneous cell population, such as basal progenitors, apical progenitors, and ORNs, analogous to CNS.

In conclusion, the present study showed that Six1 plays a critical role in the production of basal and apical progenitors and their differentiation during $\mathrm{OE}$ development by regulating various genes, such as neuronal bHLH, neuronal repressor bHLH, 
and genes involved in Notch signaling pathway.

\section{Materials and Methods}

\section{Animals}

Mash $1^{+/-}$and Six $1^{+/-}$mice were generated as described previously (Guillemot et al., 1993; Ozaki et al., 2004). The Six1+/- mouse carries a replaced enhanced green fluorescent protein (EGFP) gene into the first coding exon of the Six 1 gene. Homozygous embryos were obtained by intercrossing male and female heterozygous mice. Gestation day 0 was established upon detection of a copulatory plug after overnight mating. The PCR primers for genotyping of embryos were described previously (Guillemot et al., 1993; Ozaki et al., 2004). The developmental stage of each set of experiments was adjusted by the number of somites. Littermates (wild type mouse, WT; Six 1 knockout homozygous mouse, Six $1^{1-\text { - }}$ ) or littermates (wild type mouse, WT; Mash1 knockout homozygous mouse, Mash $1^{-/}$) were used for comparison of the expression levels of various genes and proteins, and experiments of BrdU incorporation. WT embryos, fetuses, and mice were used in experiments designed to analyze the expression of Six 1 and Six1/other neural or sustentacular marker proteins. Mice were housed in an environmentally controlled room in the Center for Experimental Medicine of Jichi Medical University, under the guidelines for animal experiments. All experimental protocols were approved by the Ethics Review Committee for Animal Experimentation of Jichi Medical University and Kyoto University.

\section{Immunofluorescence, immunohistochemistry and BrdU incorpora- tion}

Embryos were fixed at $4{ }^{\circ} \mathrm{C}$ in $4 \%$ paraformaldehyde/ $0.1 \mathrm{M}$ phosphate buffered saline (PBS, pH 7.4) for 3-24 hours, depending on the developmental stage. For co-immunofluorescence analyses, WT or C57/BL6 embryos/mice were used. Samples were immersed in 18\% sucrose/PBS, embedded in optimal cutting temperature (OCT) compound (Sakura Finetek, Torrance, CA), then frozen on dry ice, and cut into $16-\mu \mathrm{m}$ thick frontal sections, followed by immunofluorescence or immunohistochemistry. The following primary antibodies were used: anti-Ki67 (1:2 dilution, YLEM, Rome, Italy), anti-NeuroD (1:200 dilution, Santa Cruz Biotechnology, Santa Cruz, CA), anti-Hes1 (1:200 dilution, Santa Cruz), antiPGP9.5 for Fig. 1 (1:100 dilution, Serotec, Oxford, UK) and anti-PGP9.5 for Fig. 3 (1:2,000 dilution, Research Diagnostics, Flanders, NJ), antiOMP (1:2000 dilution, Wako Pure Chemical Industries, Osaka, Japan), anti-SUS-4 (1:1,000 dilution, kindly provided by J.E. Schwob, Tufts University), anti-CK18 (1:250 dilution, Epitomics, Burlingame, CA), antiCK14 for Fig. 1 (1:40 Dilution, Novocastra, Leica Microsystems, Germany) and anti-CK14 for Fig. 5 (1:200 dilution, Progen, Heidelberg, Germany). Homemade anti-mouse Six 1 antibody was described previously (lkeda et al., 2007). The secondary antibodies for florescent staining (1:1,000 dilution) were Alexa Fluor 488 anti-mouse, Alexa Fluor 488 anti-sheep, Alexa Fluor 488 anti-guinea pig, Alexa Fluor 546 antirabbit, Alexa Fluor 546 anti-goat, Alexa Fluor 546 anti-mouse, Alexa Fluor 633 anti-goat, and Alexa Fluor 633 anti-rabbit (Molecular Probes/Invitrogen, Carlsbad, CA). Hoechst 33258 (Hoechst, Serva, Heidelberg, Germany) or 4,6-diamidino-2-phenylindole (DAPI, Sigma, St. Louis, MO) was used for nuclear staining. Images of immunofluorescence samples were obtained with $20 \mathrm{X}$ or $40 \mathrm{X}$ objectives of an Olympus FV1000 confocal microscope. For bright-field staining, ABC-AP kit (Vector Laboratories, Burlingame, CA) was used followed by counterstaining with hematoxylin. For experiments of BrdU incorporation of Fig. 1, 2-month-old male mice were injected intraperitoneally with BrdU (40 mg/kg, Sigma) and then sacrificed 60 min later. BrdU-Immunofluorescence was performed using Cell proliferation kit (GE Healthcare, Amersham Place, Buckinghamshire, UK) and Alexa Fluor 488 anti-mouse antibody. Experiments of BrdU incorporation for Fig. 3 were performed as described previously, using 8$\mu \mathrm{m}$ thick paraffin-embedded sections and counterstained with hematoxylin (Ikeda et al., 2007). The upper side is the dorsal and the right side is the medial side in the panels of related figures, unless otherwise indicated in the figure legends. Representative samples of at least three sets of different embryos, which showed similar results, are shown in the figures.

\section{RNA probes and in situ hybridization}

In situ hybridization was performed on $8-\mu \mathrm{m}$ thick paraffin frontal sections using single-stranded digoxigenin-UTP (Roche Diagnostics, Basel, Switzerland)-labeled riboprobes as described previously (lkeda et al., 2007). Hybridization was performed at $65^{\circ} \mathrm{C}$. Signals were detected with an anti-digoxigenin antibody (Roche) and NBT-BCIP (Roche) for chromogen. The probes used were as follows: Six1, provided by P. Gruss; Mash1, by D.J. Anderson; Ngn1, by Q. Ma; NeuroD, by E. Cole and M. Bronner-Fraser; Phd1, by T. Saito; Lhx2, by P. Choi and C. Dulac; Notch1, Notch2, Jagged1, and Jagged2, by G. Weinmaster; Lfng, by D.K. Wu; Hes1, Hes5, and Ebf1, as described previously (Ikeda et al., 2007). In each figure panel, the upper side is the dorsal side, unless otherwise indicated. Representative samples of at least three sets of different embryos, which showed similar results, are shown in the figures.

\section{Acknowledgments}

We are grateful to Peter Gruss, David J. Anderson, Qiufu Ma, Edward G. Coles, Marianne Bronner-Fraser, Tetsuichiro Saito, Philip Choi, Catherine Dulac, Gerry Weinmaster, Doris K. Wu, and James E. Schwob for kindly providing the materials listed in the text, and to François Guillemot for Mash1-knockout mice. We also thank Shigeru Sato and Hiroshi Yajima for critical reading of and comments on the manuscript, and Kanako Mogi, Yuko Suto, Miho Akima, Emiko Ataka, Zenichi Ando, and Kuniko Takase for the technical assistance. This work was supported by grants from the Ministry of Education, Culture, Sports, Science, and Technology of Japan (20590177 to K.I.) and by Support Program for Scientific Research Platform in Private Universities (SPSRP) to JMU.

\section{References}

BEITES, CL, KAWAUCHI, S, CROCKER, CE and CALOFO, AL. (2005). Identification and molecular regulation of neural stem cells in the olfactory epithelium. Exp Cell Res 306: 309-316.

BOSMAN EA, QUINT E, FUCHS H, HRABÉ ANGELIS M, STEEL KP. (2009). Catweasel mice: A novel role for Six1 in sensory patch development and a model for branchio-oto-renal syndrome. Dev Biol 328: 285-296.

BYSTRON I, RAKIC P, MOLNÁR Z, BLAKEMORE C. (2006). The first neurons of the human cerebral cortex. Nat Neurosci 9: 880-886.

CAGGIANO M, KAUER JS, HUNTER DD. (1994). Globose basal cells are neuronal progenitors in the olfactory epithelium: A lineage analysis using a replicationincompetent retrovirus. Neuron 13: 339-352.

CALOF AL, CHIKARAISHI DM. (1989). Analysis of neurogenesis in a mammalian neuroepithelium: Proliferation and differentiation of an olfactory neuron precursor in vitro. Neuron 3: 115-127.

CALOF AL, BONNIN A, CROCKER C, KAWAUCHI S, MURRAY RC, SHOU J, WU $\mathrm{H}-\mathrm{H}$. (2002). Progenitor cells of the olfactory receptor neuron lineage. Microsc Res Tech 58: 176-188.

CARSON C, MURDOCH B, ROSKAMS AJ. (2006). Notch 2 and Notch 1/3 segregate to neuronal and glial lineages of the developing olfactory epithelium. Dev Dyn 235: 1678-1688.

CARTER LA, MACDONALD JL, ROSKAMS AJ. (2004). Olfactory horizontal basal cells demonstrate a conserved multipotent progenitor phenotype. J Neurosci 24: 5670-5683.

CAU E, GRADWOHL G, FODE C, GUILLEMOT F. (1997). Mash1 activates a cascade of bHLH regulators in olfactory neuron progenitors. Development 124 : 1611-1621.

CAU E, GRADWOHL G, CASAROSA S, KAGEYAMA R, GUILLEMOT F. (2000). Hes genes regulate sequential stages of neurogenesis in the olfactory epithelium. Development 127: 2323-2332.

CAU E, CASAROSA S, GUILLEMOT F. (2002). Mash1 and Ngn1 control distinct steps of determination and differentiation in the olfactory sensory neuron 
lineage. Development 129: 1871-1880

CHEN B, KIM E-H, XU P-X. (2009). Initiation of olfactory placode development and neurogenesis is blocked in mice lacking both Six1 and Six4. Dev Biol 326: 7585.

CHEN Y, GETCHELL ML, DING X, GETCHELL TV. (1992). Immunolocalization of two cytochrome $\mathrm{P} 450$ isozymes in rat nasal chemosensory tissue. Neuroreport 3: 749-752.

CHRISTENSEN KL, PATRICK AN, MCCOY EL, FORD HL. (2008). The Six family of homeobox genes in development and cancer. Adv Cancer Res 101: 93-126.

CORBIN JG, GAIANO N, JULIANO SL, POLUCH S, STANCIK E, HAYDAR TF. (2008). Regulation of neural progenitor cell development in the nervous system. $\checkmark$ Neurochem 106: 2272-2287.

DE LA POMPA JL, WAKEHAM A, CORREIA KM, SAMPER E, BROWN S, AGUILERA RJ, NAKANO T, HONJO T, MAK TW, ROSSANT J, CONLON RA (1997). Conservation of the Notch signalling pathway in mammalian neurogenesis. Development 124: 1139-1148.

DING X, COON MJ. (1988). Purification and characterization of two unique forms of cytochrome P-450 from rabbit nasal microsomes. Biochemistry 27: 83308337

FARBMAN AI. 1992. Cell Biology of Olfaction. Cambridge University Press, New York, pp. 1-282.

GAIANO N, NYE JS, FISHELL G. (2000). Radial glial identity is promoted by Notch1 signaling in the murine forebrain. Neuron 26: 395-404.

GOLDSTEIN BJ, SCHWOB JE. (1996). Analysis of the globose basal cell compartment in rat olfactory epithelium using GBC-1, a new monoclonal antibody against globose basal cells. J Neurosci 16: 4005-4016.

GORDON MK, MUMM JS, DAVIS RA, HOLCOMB JD, CALOF AL. (1995). Dynamics of MASH1 expression in vitro and in vivo suggest a non-stem cell site of MASH1 action in the olfactory receptor neuron lineage. Mol Cell Neurosci 6: 363-379.

GRAZIADEI PPC, MONTI GRAZIADEI GA. (1979). Neurogenesis and neuron regeneration in the olfactory system of mammals. I. Morphological aspects of differentiation and structural organization of the olfactory sensory neurons. $J$ Neurocytol 8: 1-18

GUILLEMOT F, LO L-C, JOHNSON JE, AUERBACH A, ANDERSON DJ, JOYNER AL. (1993). Mammalian achaete-scute homolog 1 is required for the early development of olfactory and autonomic neurons. Cell 75: 463-476.

HATAKEYAMA J, KAGEYAMA R. (2006). Notch1 expression is spatiotemporally correlated with neurogenesis and negatively regulated by Notch1-independent Hes genes in the developing nervous system. Cereb Cortex 16: i132-i137.

HITOSHIS, ALEXSON T, TROPEPE V, DONOVIEL D, ELIA AJ, NYE JS, CONLON RA, MAK TW, BERNSTEIN A, VAN DER KOOY D. (2002). Notch pathway molecules are essential for the maintenance, but not the generation, of mammalian neural stem cells. Genes Dev 16: 846-858.

HOLBROOK EH, SZUMOWSKI KEM, SCHWOB JE. (1995). An immunochemical, ultrastructural, and developmental characterization of the horizontal basal cells of rat olfactory epithelium. J Comp Neurol 363: 129-146.

HUARD JMT, YOUNGENTOB SL, GOLDSTEIN BJ, LUSKIN MB, SCHWOB JE. (1998). Adult olfactory epithelium contains multipotent progenitors that give rise to neurons and non-neural cells. J Comp Neurol 400: 469-486.

IATROPOULOS MJ, WILLIAMS GM. (1996). Proliferation markers. Exp Toxic Pathol 48: 175-181.

IKEDA K, OOKAWARA S, SATO S, ANDO Z, KAGEYAMA R, KAWAKAMI K. (2007). Six 1 is essential for early neurogenesis in the development of olfactory epithelium. Dev Biol 311: 53-68.

IWAI N, ZHOU Z, ROOP DR, BEHRINGER RR. (2008). Horizontal basal cells are multipotent progenitors in normal and injured adult olfactory epithelium. Stem Cells 26: 1298-1306.

JARRIAULT S, BROU C, LOGEAT F, SCHROETER EH, KOPAN R, ISRAEL A. (1995). Signalling downstream of activated mammalian Notch. Nature 377:355358.

JARRIAULT S, LE BAIL O, HIRSINGER E, POURQUIÉ O, LOGEAT F, STRONG CF, BROU C, SEIDAH NG, ISRAËL A. (1998). Delta-1 activation of Notch-1 signaling results in HES-1 transactivation. Mol Cell Biol 18: 7423-7431.

KAGEYAMA R, NAKANISHI S. (1997). Helix-loop-helix factors in growth and differentiation of the vertebrate nervous system. Curr Opin Genet Dev 7: 659665.

KAWAKAMI K, SATO S, OZAKI H, IKEDA K. (2000). Six family genes-structure and function as transcription factors and their roles in development. Bioessays 22 616-626

LATHIA JD, MATTSON MP, CHENG A. (2008). Notch: from neural development to neurological disorders. J Neurochem 107: 1471-1481.

LEUNG CT, COULOMBE PA, REED RR. (2007). Contribution of olfactory neural stem cells to tissue maintenance and regeneration. Nat Neurosci 10: 720-726.

LINDSAY SL, RIDDELL JS, BARNETT SC. (2010). Olfactory mucosa for transplant-mediated repair: A complex tissue for a complex injury? Glia 58: 125-134.

LINDSELL CE, BOULTER J, DISIBIO G,nGOSSLER A, WEINMASTER G. (1996). Expression patterns of Jagged, Delta1, Notch1, Notch2, and Notch3 genes identify ligand-receptor pairs that may function in neural development. $\mathrm{Mol} \mathrm{Ce} / \mathrm{l}$ Neurosci 8: 14-27.

MANGLAPUS GL, YOUNGENTOB SL, SCHWOB JE. (2004). Expression patterns of basic helix-loop-helix transcription factors define subsets of olfactory progenitor cells. J Comp Neurol 479: 216-233.

MARSHALL CT, LU C, WINSTEAD W, ZHANG X, XIAO M, HARDING G, KLUEBER KM, ROISEN FJ. (2006). The therapeutic potential of human olfactory-derived stem cells. Histol Histopathol 21: 633-643.

MITSIADIS TA, GAYET O, ZHANG N, CARROLL P. (2001). Expression of Deltex during mouse embryogenesis: comparison with Notch1, 2 and 3 expression. Mech Dev 109: 399-403.

MURRAY RC, NAVI D, FESENKO J, LANDER AD, CALOF AL. (2003). Widespread defects in the primary olfactory pathway caused by loss of Mash1 function. $J$ Neurosci 23: 1769-1780.

NICOLAY DJ, DOUCETTE JR, NAZARALI AJ. (2006). Transcriptional regulation of neurogenesis in the olfactory epithelium. Cell Mol Neurobiol 26: 803-821.

NOMURA T, TAKAHASHI S, USHIKI T. (2004). Cytoarchitecture of the normal rat olfactory epithelium: Light and scanning electron microscopic studies. Arch Histol Cytol 67: 159-170.

OHTSUKA T, ISHIBASHI M, GRADWOHL G, NAKANISHI S, GUILLEMOT F KAGEYAMA R. (1999). Hes 1 and Hes5 as Notch effectors in mammalian neuronal differentiation. EMBO J 18: 2196-2207.

OZAKI H, NAKAMURA K, FUNAHASHI J, IKEDA K, YAMADA G, TOKANO H, OKAMURA HO, KITAMURA K, MUTO S, KOTAKI H, SUDO K, HORAI R, IWAKURA Y, KAWAKAMI K. (2004). Six1 controls patterning of the mouse otic vesicle. Development 131: 551-562

RODRIGUEZ S, SICKLES HM, DELEONARDIS C, ALCARAZ A, GRIDLEY T, LIN DM. (2008). Notch2 is required for maintaining sustentacular cell function in the adult mouse main olfactory epithelium. Dev Biol 314: 40-58.

SCHWANZEL-FUKUDA M, ABRAHAM S, CROSSIN KL, EDELMAN GM, PFAFF DW. (1992). Immunocytochemical demonstration of neural cell adhesion molecule (NCAM) along the migration route of luteinizing hormone-releasing hormone (LHRH) neurons in mice. J Comp Neurol 321: 1-18.

SCHWARTING GA, GRIDLEY T, HENION TR. (2007). Notch1 expression and ligand interactions in progenitor cells of the mouse olfactory epithelium. $J \mathrm{Mol}$ Hist 38: 543-553.

SCHWOB JE, HUARD JMT, LUSKIN MB, YOUNGENTOB SL. (1994). Retroviral lineage studies of the rat olfactory epithelium. Chemical Senses 19: 671-682.

SCHWOB JE. (2002). Neural regeneration and the peripheral olfactory system. Anat Rec 269: 33-49.

SHIMIZU K, CHIBA S, SAITO T, KUMANO K, HAMADA Y, HIRAI H. (2002). Functional diversity among Notch1, Notch2, and Notch3 receptors. Biochem Biophys Res Commun 291: 775-779.

SOLECKI DJ, LIU XL, TOMODA T, FANG Y, HATTEN ME. (2001). Activated Notch2 signaling inhibits differentiation of cerebellar granule neuron precursors by maintaining proliferation. Neuron 31: 557-568.

SMART IHM. (1971). Location and orientation of mitotic figures in the developing mouse olfactory epithelium. J Anat 109: 243-251.

SUZUKI Y, TAKEDA M. (1991). Keratins in the developing olfactory epithelia. Dev Brain Res 59: 171-178.

TANIGAKI K, NOGAKI F, TAKAHASHI J, TASHIRO K, KUROOKA H, HONJO T. (2001). Notch1 and Notch3 instructively restrict bFGF-responsive multipoten 
neural progenitor cells to an astroglial fate. Neuron 29: 45-55.

TIETJEN I, RIHEL JM, CAO Y, KOENTGES G, ZAKHARY L, DULAC C. (2003). Single-cell transcriptional analysis of neuronal progenitors. Neuron 38: 161175.

WEILER E, BENALI A. (2005). Olfactory epithelia differentially express neuronal markers. J Neurocytol 34: 217-240.

WEILER E, FARBMAN AI. (1998). Supporting cell proliferation in the olfactory epithelium decreases postnatally. Glia 22: 315-328.

WHITLOCK KE, WESTERFIELD M. (1998). A transient population of neurons pioneers the olfactory pathway in the zebrafish. J Neurosci 18: 8919-8927.

WILLIAMS SK, GILBEY T, BARNETT SC. (2004). Immunohistochemical studies of the cellular changes in the peripheral olfactory system after zinc sulfate nasal irrigation. Neurochem Res 29: 891-901.

YOON K, GAIANO N. (2005). Notch signaling in the mammalian central nervous system: insights from mouse mutants. Nat Neurosci 8: 709-715.

ZHENG W, HUANG L, WEI Z-B, SILVIUS D, TANG B, XU P-X. (2003). The role of Six1 in mammalian auditory system development. Development 130: 39894000 .

\section{Further Related Reading, published previously in the Int. J. Dev. Biol.}

See our recent Special Issue Placenta edited by Joan S. Hunt and Kent L. Thornburg at: http://www.ijdb.ehu.es/web/contents.php?vol=54\&issue=2-3

The preplacodal region: an ectodermal domain with multipotential progenitors that contribute to sense organs and cranial sensory ganglia

Andrea Streit

Int. J. Dev. Biol. (2007) 51: 447-461

Molecular evolution of the vertebrate mechanosensory cell and ear Bernd Fritzsch, Kirk W. Beisel, Sarah Pauley and Garrett Soukup Int. J. Dev. Biol. (2007) 51: 663-678

Experimental study of early olfactory neuron differentiation and nerve formation using quail-chick chimeras Fabrice L. Lalloué and Christiane S. Ayer-Le Lièvre Int. J. Dev. Biol. (2005) 49: 193-200

Single-cell transcriptional profiles and spatial patterning of the mammalian olfactory epithelium lan Tietjen, Jason Rihel and Catherine G. Dulac Int. J. Dev. Biol. (2005) 49: 201-207

Tissue and developmental distribution of Six family gene products H Ohto, T Takizawa, T Saito, M Kobayashi, K Ikeda and K Kawakami Int. J. Dev. Biol. (1998) 42: 141-148
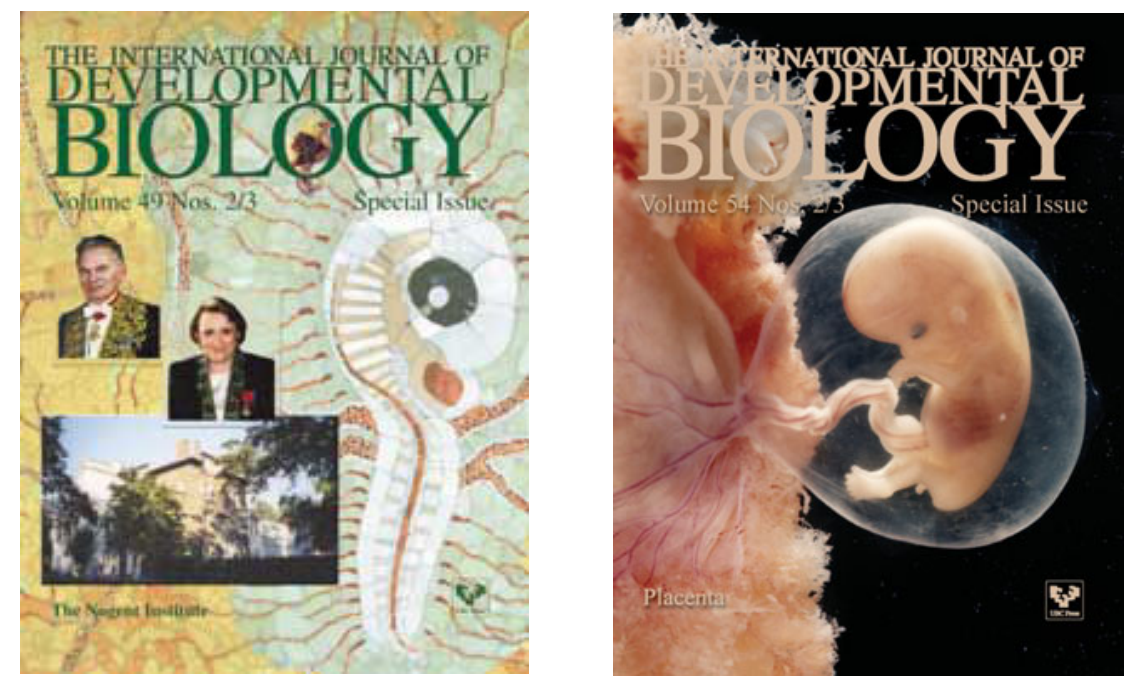

5 yr ISI Impact Factor $(2009)=3.253$

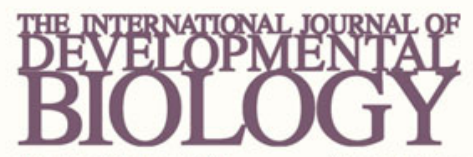

Volume 54 Nos. 6/7 Special Issue

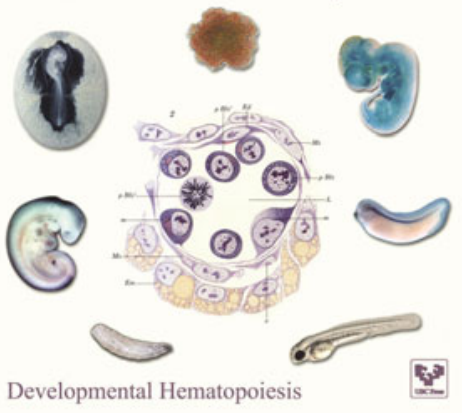

